\title{
ANALISIS RESIKO KESELAMATAN DAN KESEHATAN KERJA PADA PEKERJA BAGIAN PENGEMASAN MINIPACK MENGGUNAKAN METODE JOB SAFETY ANALYSIS (JSA) PADA CV. $\mathrm{XYZ}$
}

\author{
Atyanti Dyah Prabaswari ${ }^{1}$,Maharani Maulda ${ }^{2}$, Amarria Dila Sari ${ }^{3}$ \\ ${ }^{12,3)}$ Fakultas Teknologi Industri, Prodi Teknik Industri, Universitas Islam Indonesia \\ Jl. Kaliurang Km. 14.5, Yogyakarta 55584 \\ Email: atyanti.dyah@uii.ac.id
}

\begin{abstract}
ABSTRAK
Penerapan konsep Keselamatan dan Kesehatan Kerja (K3)di perusahaan dapat menjadi s arana utuk mencegah terjadinya risiko kecelakaan kerja bagi pekerja. Pabrik Susu XYZ merupakan salah satu pabrik susu pasteurisasi dan yogurt di Indonesia yang memiliki angka kecelakaan kerja pada tiap bagian. Angka kecelakaan kerja tertinggi terjadi pada bagian pengemasan karena pekerja tidak menggunakan Alat Pelindung Diri (APD) sesuai standar pabrik. Penelitian ini bertujuan untuk mengidentifikasi risiko kerja dengan menggunakan Job Safety Analysis (JSA) dan analisis risiko semi kuantitatif AS/NZS 4360. Berdasarkan identifikasi risiko menggunakan JSA diketahui bahwa tiap pekerjaan pada bagian pengemasan minipack telah mempunyai pengendalian risiko tetapi belum optimal. Berdasarkan perhitungan analisis risiko semi kuantitatif menggunakan AS/NZS 4360 (1999), pekerjaan yang memiliki nilai risiko kecelakaan kerja tertinggi adalah pekerjaan mengatur volume dan pemasangan kemasan minipack dengan skor nilai 270. Pengendalian risiko yang dapat dilakukan oleh Pabrik Susu XYZ untuk mengurangi kecelakaan kerja adalah membentuk tim P2K3 dan menerapkan Behavior Based Safety (BBS) bagi keseluruhan pekerja.
\end{abstract}

Kata kunci: Keselamatan dan Kesehatan Kerja (K3), Job Safety Analysis(JSA), AS/NZS 4360

\begin{abstract}
Implementation of Occupational Safety and Health (OSH) in the company can prevent accident for workers. Milk factory XYZ is one of pasteurized milk and yogurt factories in Indonesia which has accident rate in each section. The highest rate of accidents occurs in the packing section because the workers not using Personal Protective Equipment (PPE). The PPE is one of factory standard to OSH.This study aims to identify job risk by using Job Safety Analysis (JSA) and semi quantitative risk analysis of AS/NZS 4360. Based on risk identification using JSA, each of job on minipack packaging has risk control but not optimal. Based on semi quantitative risk analysis using AS/NZS 4360 (1999), the highest risk is on regulating the volume and installation of minipack packaging. The score of the jobs is 270 . XYZ milk factory can reducing accident with forming committee for safety and health (P2K3) team and implement behaviour Based Safety (BBS).
\end{abstract}

Keywords: Occupational Safety and Health (OSH), Job Safety Analysis (JSA), AS/NZS 4360

\section{Pendahuluan}

Pembangunan berkelanjutan di mainkan penting oleh Usaha kecil dan menengah (UKM) [6]. Hal ini dapat menciptakan lapangan kerja dan pertumbuhan ekonomi. Proses berkembangnya industri dan UKM pada masyarakat Indonesia diiringi oleh resiko bahaya yang lebih besar dan beragam masalah karena adanya perubahan/alih teknologi. Teknologi ini berperan dalam penggunaan mesin dan oeralatan kerja yang semakin kompleks dalam mendukung berjalannya proses produksi. Masalah kesehatan dan keselamatan kerja dapat ditimbulkan oleh perkembangan teknologi ters ebut [10]

Baru-baru ini, dilaporkan dari ILO bahwa sekitar 317 juta kecelakaan kerja terjadi secara global setiap tahun dimana sekitar 6300 orang meninggal dunia [4]. Pada laporan secara global, G4 berfokus pada membentuk 
kelompok kerja kesehatan dan keselamatan kerja untuk mempromosikan keberlanjutan dan transparansi dalam organis asi, hal tersebut dinyatakan oleh GRI pada tahun 2012 [6].

CV. XYZ ini merupakan perusahaan yang memiliki aktivitas produksi dan mengemas produknya dalam bentuk kemasan cup dan botol. Potensi bahaya banyak terdapat ditempat ini dan dapat menimbulkan kerugian baik pada perusahaan maupun pekerja. Penerapan konsep K3 di perusahaan dapat menjadi salah satu sarana untuk mencegah terjadinya kecelakaan akibat kerja dan dapat menjadi salah satu sarana mengetahui potensi pekerjaan yang memiliki resiko tinggi.

Bagian pengemasan pada CV. XYZ ini memiliki angka kecelakaan kerja paling tinggi setiap tahunnya. Perusahaan telah menyediakan Alat Pelindung Diri (APD) berupa sepatu boots, topi, masker, dan sarung tangan. Namun menurut hasil observasi, banyak pekerja yang tidak menggunakan APD secara lengkap sesuai peraturan perusahaan. Supervisor bagian pengemasan mengatakan bahwa sejauh ini belum ada pengawasan tentang K3. Sedangkan menurut para pekerja bagian pengemasan, APD berupa masker dan sarung tangan masih dalam jumlah terbatas.

\section{Metode Penelitian}

\section{Pengumpulan Data}

Penelitian lapangan dilakukan untuk meninjau langsung ke lokasi sehingga peneliti dapat mengamati secara langsung. Pengumpulan data selanjutnya menggunakan metode wawancara untuk mendapatkan informasi yang dibutuhkan terkait dengan penelitian dari pihak-pihak yang berperan langsung dalam kegiatan.

Observasi langsung dan wawancara pada pekerja dilakukan pada bagian pengemasan minipack CV. XYZ. Hasil pengamatan dicatat pada lembar JSA semi kuantitatif berdasarkan Risk Managemen AS/NZS 4360 (1999) [1].

JSA adalah sebuah teknik pencegahan kecelakaan yang digunakan untuk mengidentifikasi potensi resiko dan bahaya yang berkaitan dengan suatu pekerja serta memberikan pengendelian resiko untuk mengurangi resiko dan bahaya tersebut [8]. Saat melakukan JSA terdapat empat langkah utama yang harus dilakukan berdasarkan OSHAcademy Course 706 Study Guide [5]:

1. Memilih pekerjaan yang akan dianalis is

2. Membagi pekerjaan menjadi beberapa langkah pokok pekerjaan

3. Mengidentifikasi resiko atau bahaya yang potensial

4. Mengendalikan resiko dengan memberikan perbaikan untuk mengurangi potensi resiko atau bahaya yang mungkin terjadi.

JSA digunakan untuk membedah tugas perakitan menjadi subtugas dan menganalisis subtugas untuk bahaya yang mungkin terjadi serta solusi untuk resiko yang dirasakan [7]. Lingkungan kerja dapat dikendalikan melalui JSA sehingga kemungkinan terjadinya insiden berkurang [9].

\section{Pengendalian dan Analisis Risiko}

Keselamatan dan kesehatan kerja (K3) merupakan instrumen yang melindungi pekerja, perusahaan, lingkungan hidup, dan masyarakat sekitar dari bahaya akibat kecelakaan kerja. Perlindungan tersebut merupakan hak asasi yang wajib dipenuhi oleh perusahaan [14]. Adanya penerapan teknologi pengendalian Keselamatan dan Kesehatan Kerja, diharapkan tenaga kerja akan mencapai ketahanan fisik dan memiliki tingkat kesehatan yang tinggi. Disamping itu, Keselamatan dan Kesehatan Kerja juga diharapkan untuk dapat menciptakan kenyaman kerja dan keselamatan kerja yang tinggi [13].

Menurut OHSAS 18001, risiko K3 berkaitan dengan sumber bahaya yang timbul dalam aktivitas bisnis yang menyangkut aspek manusia, peralatan, material, dan lingkungan kerja. Umumnya risiko K3 dikonotasikan sebagai konotasi negatif antara lain : kecelakaan terhadap manusia dan aset perusahaan, kebakaran dan peledakan, penyakit akibat kerja, kerusakan sarana produksi, gangguan operasi [12].

Analisis resiko adalah suatu kegiatan sistematik dengan menggunakan informasi yang ada untuk mendeterminasi seberapa besar konsequensi (severity) dan tingkat keseringan (likelihood) suatu kejadian yang ditimbulkan (AS/NZS4360, 1999). Berdasarkan AZ/NZS 4360 (1999) terdapat tiga metode yang dapat digunakan untuk menganalis is resiko di tempat kerja, diantaranya adalah sebagaiberikut :

1. Analisis Resiko Kualitatif 
Metode ini menggunakan bentuk matriks resiko dengan dua parameter, yaitu peluang dan akibat. Skala ukur konsekuensi dan kecenderungan (likehood) secara kualitatif menurut Risk Management AS/NZS (1999) [1].

2. Analisis Resiko Semi Kuantitatif

Berdasarkan AS/NZS 4360 (1999) [1], analisis Semi Kuantitatif mempertimbangkan kemungkinan untuk menggabungkan dua elemen, yaitu probabilitas (likehood) dan paparan (exposure) sebagai frekuensi.

3. Analisis Resiko Kuantitatif

Analisis resiko kuantitatif merupakan analisis resiko yang mendifinisikan kemungkinan outcome. Total resiko disini merupakan total dari semua potensiresiko yang mungkin terjadi.

Penyelesaian masalah pada CV. XYZ menggunakan metode semi kuantitatif, hal ini didasarkan pertimbangan bahwa metode ini lebih akurat dan cepat dibandingkan metode kualitatif [3]. Tingkat risiko pada analisis semi kuantitatif adalah perkalian dari:

$$
\text { Nilai risiko }=\text { Consequences }(C) x \text { Exposure }(E) x \text { Likehood }(L)
$$

Metode ini terdapat tiga unsuryang dijadikan pertimbangan [1]:

1. Konsekuensi(Consequences)

Nilai yang menggambarkan suatu keparahan dari efek yang digtimbulkan oleh sumber risiko pada tahapan suatu pekerjaan. Hal ini dapat dilihat pada Tabel 1.

Tabel 1. Skala konsekuensi semi kuantitatif

\begin{tabular}{|c|c|c|}
\hline Kategori & Deskripsi & Rating \\
\hline Catasthropic & $\begin{array}{l}\text { Kerusakan yang sangat parah dengan kerugian diatas } \$ 1.000 .000 \text {, terhentinya } \\
\text { aktivitas, kerusakan besar-besaran dan menetap terhadap lingkungan. }\end{array}$ & 100 \\
\hline Disaster & $\begin{array}{l}\text { Kematian, kerusakan setempat dan menetap terhadap lingkungan dengan kerugian } \\
\$ 500.000-\$ 2.000 .000 \text {. }\end{array}$ & 50 \\
\hline Very serious & $\begin{array}{l}\text { Cacat atau penyakit yang menetap, kerusakan sementara terhadap lingkungan, kerugian } \\
\$ 50.000-\$ 500.000 \text {. }\end{array}$ & 25 \\
\hline Serious & $\begin{array}{l}\text { Cedera atau penyakit serius tetaapi bersifat sementara, efek yang merugikan terhadap } \\
\text { lingkungan, kerugian } \$ 5000-\$ 50.000 \text {. }\end{array}$ & 15 \\
\hline Important & $\begin{array}{l}\text { Membutuhkan penanganan medis, kerugian } \$ 50-\$ 5000 \text {, efeknya dirasakan tetapi tidak } \\
\text { terlalu merugikan. }\end{array}$ & 5 \\
\hline Noticeable & $\begin{array}{l}\text { Luka ringan, memar atau penyakit yang ringan, kerusakan kecil dengan kerugian } \\
\text { produk sebesar }<\$ 500 \text {, kerugian setempat yang sangat kecil dengan efek yang juga } \\
\text { setempat. }\end{array}$ & 1 \\
\hline
\end{tabular}

2. Paparan (Exposure)

Paparan menggambarkan tingkat frekuensi interaksi antara sumber risiko yang terdapat di tempat kerja dengan pekerja serta menggambarkan kesempatan yang terjadi. Hal ini dapat dilihat pada Tabel 2.

Tabel 2. Skala paparan semi Kuantitatif

\begin{tabular}{llc}
\hline \multicolumn{1}{c}{ Kategori } & \multicolumn{1}{c}{ Deskripsi } & Rating \\
\hline Continuously & Terjadi secara terus-menerus atau setiap hari & 10 \\
\hline Frequent & Terjadi kira-kira satu kali setiap hari & 6 \\
\hline Occasionaly & $\begin{array}{l}\text { Terjadi sekali seminggu sampai dengan sekali satu } \\
\text { bulan }\end{array}$ & 3 \\
\hline Infrequent & $\begin{array}{l}\text { Terjadi sekali sebulan sampai dengan sekali dalam satu } \\
\text { tahun }\end{array}$ & 2 \\
\hline Rare & Pernah terjadi tapi sangat jarang & 1 \\
\hline Very Rare & Belum pernah terjadi & 0,5 \\
\hline
\end{tabular}

3. Kemungkinan (Likehood)

Kemungkinan merupakan nilai yang menggambarkan suatu kecenderungan terjadinya konsekuensi dari sumber risiko pada setiap tahapan pekerjaan. Hal ini dapat dilihat pada Tabel 3 . 
Tabel 3. Skala kemungkinan semi kuantitatif

\begin{tabular}{llc}
\hline \multicolumn{1}{c}{ Kategori } & \multicolumn{1}{c}{ Deskripsi } & Rating \\
\hline Almost certain & $\begin{array}{l}\text { Akibat yang paling mungkin timbul apabila } \\
\text { kerjadian tersebut terjadi }\end{array}$ & 10 \\
\hline Likely & Kemungkinan terjadi 50-50 & 6 \\
\hline Unusual & Kemungkinan terjadi tapi jarang & 3 \\
\hline Remotely possible & $\begin{array}{l}\text { Kejadian yang sangat kecil kemungkinannya untuk } \\
\text { terjadi }\end{array}$ & 0,5 \\
\hline Cenceivable & $\begin{array}{l}\text { Mungkin terjadi, namun belum pernah terjadi } \\
\text { meskipun dengan paparan yang bertahun-tahun }\end{array}$ & 0,1 \\
\hline Practically impossible & $\begin{array}{l}\text { Tidak mungkin terjadi atau sangat tidak mungkin } \\
\text { terjadi }\end{array}$ & \\
\hline
\end{tabular}

Kemudian hasil nilai risiko dapat dilihat pada Tabel 4.

Tabel 4. Kategori tingkat risiko analisis semi kuantitatif

\begin{tabular}{ccl}
\hline Tingkat Risiko & Comment & \multicolumn{1}{c}{ Tindakan } \\
\hline$>$ V50 & Very high & $\begin{array}{l}\text { Aktivitas dihentikan sampai risiko dikurangi } \\
\text { hingga mencapai batas yang diperbolehkan atau } \\
\text { diterima }\end{array}$ \\
\hline $\mathbf{1 8 0}-\mathbf{3 5 0}$ & Priority 1 & Perlu pengendalian sesegera mungkin \\
\hline $\mathbf{7 0}-\mathbf{1 8 0}$ & Substantial & Mengharuskan adanya perbaikan teknis \\
\hline $\mathbf{2 0}-\mathbf{7 0}$ & Priority 3 & Perlu diawasi secara berkesinambungan \\
\hline$<\mathbf{2 0}$ & Acceptable & $\begin{array}{l}\text { Intensitas yang menimbulkan risiko dikurangi } \\
\text { seminimal mungkin }\end{array}$ \\
\hline
\end{tabular}

\section{Hasil dan Pembahasan}

Hasil pengamatan dicatat pada lembar kerja Job Safety Analysis (JSA) semi kuantitatif berdasarkan Risk Management AS/NZS 4360 (1999) [1]. Data hasil observasidapat dilihat pada Tabel 5.

Tabel 5. Hasil identifikasi resiko

\begin{tabular}{|c|c|c|c|c|c|c|}
\hline No & Operator & Posisi & $\begin{array}{l}\text { Rincian } \\
\text { Pekerjaan }\end{array}$ & Kondisi & Resiko & $\begin{array}{c}\text { Pengendalian } \\
\text { saat ini }\end{array}$ \\
\hline \multirow[t]{3}{*}{1} & \multirow[t]{3}{*}{ A } & \multirow[t]{3}{*}{$\begin{array}{l}\text { Operator } \\
\text { mesin } \\
\text { pengemasan } \\
\text { minipack } \\
\text { bagian } \\
\text { belakang }\end{array}$} & $\begin{array}{l}\text { Menyalakan } \\
\text { power mesin }\end{array}$ & $\begin{array}{l}\text { Tombol power mesin } \\
\text { berada pada ketinggian } \\
<1 \mathrm{~m} \text {, tidak ada tangga } \\
\text { atau handrail untuk } \\
\text { operator berpegangan }\end{array}$ & $\begin{array}{l}\text { Tersetrum, } \\
\text { Terjatuh } \\
<1 \mathrm{~m}\end{array}$ & $\begin{array}{l}\text { Kaos tangan, } \\
\text { pelindung } \\
\text { kepala }\end{array}$ \\
\hline & & & $\begin{array}{l}\text { Memasukkan } \\
\text { bahan pengemas } \\
\text { sesuaijenis } \\
\text { produk }\end{array}$ & $\begin{array}{l}\text { Kondisi tempat kerja } \\
\text { berada pada ketinggian } \\
<1 \mathrm{~m}\end{array}$ & $\begin{array}{l}\text { Terjatuh } \\
<1 \mathrm{~m}\end{array}$ & $\begin{array}{l}\text { Kaos tangan, } \\
\text { pelindung } \\
\text { kepala }\end{array}$ \\
\hline & & & $\begin{array}{l}\text { Flusing Mesin } 1 \\
\text { sampai Mesin } 17\end{array}$ & $\begin{array}{l}\text { Kondisi tempat kerja } \\
\text { licin akibat air dari } \\
\text { Flusing yang langsung } \\
\text { dibuang ke lantai }\end{array}$ & Terpeleset & Sepatu karet \\
\hline
\end{tabular}

\begin{tabular}{ccccccc}
\hline No & Operator & Posisi & $\begin{array}{c}\text { Rincian } \\
\text { Pekerjaan }\end{array}$ & Kondisi & Resiko & $\begin{array}{c}\text { Pengendalian } \\
\text { saat ini }\end{array}$ \\
\hline $\mathbf{2}$ & B & Operator & Menggantijalur & Kondisi tempat kerja & Terpeleset & Sepatu karet \\
\hline
\end{tabular}




\begin{tabular}{|c|c|c|c|c|c|c|}
\hline & & \multirow{2}{*}{$\begin{array}{l}\text { mesin } \\
\text { pengemasan } \\
\text { minipack } \\
\text { bagian depan }\end{array}$} & $\begin{array}{l}\text { pipa air ke jalur } \\
\text { susu }\end{array}$ & \multicolumn{3}{|l|}{$\begin{array}{l}\text { licin akibat ceceran air } \\
\text { dan susu dari pergantian } \\
\text { pipa dan pompa }\end{array}$} \\
\hline & & & $\begin{array}{l}\text { Mengatur } \\
\text { volume dan } \\
\text { pemasangan } \\
\text { kemasan } \\
\text { minipack }\end{array}$ & $\begin{array}{l}\text { Mengatur kemasan } \\
\text { Minipack menggunakan } \\
\text { tangan tanpa } \\
\text { mengenakan kaos tangan } \\
\text { dengan keadaan mesin } \\
\text { cetakan panas dan cepat }\end{array}$ & $\begin{array}{l}\text { Luka } \\
\text { bakar, } \\
\text { terpotong }\end{array}$ & $\begin{array}{l}\text { Kaos tangan } \\
\text { (jumlah } \\
\text { terbatas) }\end{array}$ \\
\hline \multirow[t]{2}{*}{3} & $\mathrm{C}$ & $\begin{array}{l}\text { Operator } \\
\text { pengemasan } \\
\text { minipack }\end{array}$ & $\begin{array}{l}\text { Mengemas susu } \\
\text { minipack ke } \\
\text { dalam plastik }\end{array}$ & $\begin{array}{l}\text { Mengemas kemasan } \\
\text { minipack yang bersuhu } \\
5 \text { derajat celcius tanpa } \\
\text { menggunkan kaos } \\
\text { tangan }\end{array}$ & $\begin{array}{l}\text { Terpapar } \\
\text { dingin }\end{array}$ & $\begin{array}{l}\text { Kaos tangan } \\
\text { (jumlah } \\
\text { terbatas) }\end{array}$ \\
\hline & & & $\begin{array}{l}\text { Menempatkan } \\
\text { plastik minipack } \\
\text { ke dalam krak } \\
\text { hingga } 5 \text { tingkat } \\
\text { krak }\end{array}$ & $\begin{array}{l}\text { Posisi duduk operator } \\
\text { terlalu rendah } \\
\text { mengakibatkan postur } \\
\text { kerja yang buruk }\end{array}$ & $\begin{array}{l}\text { Terjepit, } \\
\text { pinggang } \\
\text { terkilir }\end{array}$ & $\begin{array}{l}\text { Kaos tangan } \\
\text { (jumlah } \\
\text { terbatas) }\end{array}$ \\
\hline 4 & $\mathrm{D}$ & $\begin{array}{l}\text { Operator } \\
\text { bagian krak }\end{array}$ & $\begin{array}{l}\text { Menaikan } 5 \\
\text { tingkat krak } \\
\text { kedalam Mobil }\end{array}$ & $\begin{array}{l}\text { penyusunan krak dalam } \\
\text { mobil yang tidak sesuai } \\
\text { mengakibatkan krak } \\
\text { terjatuh }\end{array}$ & $\begin{array}{l}\text { Tertimpa } \\
\text { krak }\end{array}$ & $\begin{array}{l}\text { Masker, kaos } \\
\text { tangan }\end{array}$ \\
\hline
\end{tabular}

Hasil penilaian analisis resiko untuk bagian pengemasan minipack dijabarkan pada tabel yang disajikan dalam Tabel 6.

Tabel 6. Skor analisis risiko

\begin{tabular}{|c|c|c|c|c|c|c|c|}
\hline No & $\begin{array}{c}\text { Rincian } \\
\text { Pekerjaan }\end{array}$ & Resiko & $\begin{array}{l}\text { Sum- } \\
\text { ber }\end{array}$ & $\begin{array}{l}\text { Konsekuensi } \\
\text { (C) }\end{array}$ & $\begin{array}{l}\text { Papa- } \\
\text { ran }(\mathrm{E})\end{array}$ & $\begin{array}{l}\text { Kemungkinan } \\
\text { (L) }\end{array}$ & $\begin{array}{l}\text { Tingkat } \\
\text { Resiko }\end{array}$ \\
\hline \multirow[t]{3}{*}{1} & $\begin{array}{l}\text { Menyalakan } \\
\text { power mesin }\end{array}$ & $\begin{array}{l}\text { Tersetrum, } \\
\text { Terjatuh } \\
<1 \mathrm{~m}\end{array}$ & \multirow[t]{3}{*}{ A } & $\begin{array}{c}5 \\
\text { Important }\end{array}$ & $\begin{array}{c}1 \\
\text { Rare }\end{array}$ & $\begin{array}{c}3 \\
\text { Unusual }\end{array}$ & $\begin{array}{c}15 \\
\text { Acceptable }\end{array}$ \\
\hline & $\begin{array}{l}\text { Memasukkan } \\
\text { bahan pengemas } \\
\text { sesuai jenis } \\
\text { produk }\end{array}$ & $\begin{array}{l}\text { Terjatuh } \\
<1 \mathrm{~m}\end{array}$ & & $\begin{array}{c}5 \\
\text { Important }\end{array}$ & $\begin{array}{c}1 \\
\text { Rare }\end{array}$ & $\begin{array}{c}3 \\
\text { Unusual }\end{array}$ & $\begin{array}{c}15 \\
\text { Acceptable }\end{array}$ \\
\hline & $\begin{array}{l}\text { Flusing Mesin } 1 \\
\text { sampai Mesin } \\
17\end{array}$ & Terpeleset & & $\begin{array}{c}1 \\
\text { Noticeable }\end{array}$ & $\begin{array}{c}3 \\
\text { Accasi } \\
\text { onaly }\end{array}$ & $\begin{array}{c}10 \\
\text { Almost } \\
\text { Certain }\end{array}$ & $\begin{array}{c}30 \\
\text { Priority } 3\end{array}$ \\
\hline \multirow[t]{2}{*}{2} & $\begin{array}{l}\text { Menggantijalur } \\
\text { pipa air ke jalur } \\
\text { susu }\end{array}$ & Terpeleset & \multirow[t]{2}{*}{ B } & $\begin{array}{c}1 \\
\text { Noticeable }\end{array}$ & $\begin{array}{c}3 \\
\text { Accasi } \\
\text { onaly }\end{array}$ & $\begin{array}{c}10 \\
\text { Almost } \\
\text { Certain }\end{array}$ & $\begin{array}{c}30 \\
\text { Priority } 3\end{array}$ \\
\hline & $\begin{array}{l}\text { Mengatur } \\
\text { volume dan } \\
\text { pemasangan } \\
\text { kemasan } \\
\text { minipack }\end{array}$ & $\begin{array}{l}\text { Luka Bakar, } \\
\text { Terpotong }\end{array}$ & & $\begin{array}{c}15 \\
\text { Serious }\end{array}$ & $\begin{array}{c}3 \\
\text { Accasi } \\
\text { onaly }\end{array}$ & $\begin{array}{c}6 \\
\text { Likely }\end{array}$ & $\begin{array}{c}270 \\
\text { Priority } 1\end{array}$ \\
\hline No & $\begin{array}{c}\text { Rincian } \\
\text { Pekerjaan }\end{array}$ & Resiko & $\begin{array}{l}\text { Sum- } \\
\text { ber }\end{array}$ & $\begin{array}{c}\text { Konsekuensi } \\
\text { (C) }\end{array}$ & $\begin{array}{l}\text { Papa- } \\
\text { ran }(\mathrm{E})\end{array}$ & $\begin{array}{l}\text { Kemungkinan } \\
\text { (L) }\end{array}$ & $\begin{array}{l}\text { Tingkat } \\
\text { Resiko }\end{array}$ \\
\hline 3 & $\begin{array}{l}\text { Mengemas susu } \\
\text { minipack ke } \\
\text { dalam plastic }\end{array}$ & $\begin{array}{l}\text { Terpapar } \\
\text { dingin }\end{array}$ & $\mathrm{C}$ & $\begin{array}{c}1 \\
\text { Noticeable }\end{array}$ & $\begin{array}{c}10 \\
\text { Contin } \\
\text { ously }\end{array}$ & $\begin{array}{c}10 \\
\text { Almost } \\
\text { Certain }\end{array}$ & $\begin{array}{c}100 \\
\text { Substansial }\end{array}$ \\
\hline
\end{tabular}




\begin{tabular}{|c|c|c|c|c|c|c|c|}
\hline & $\begin{array}{l}\text { Menempatkan } \\
\text { plastik minipack } \\
\text { ke dalam krak } \\
\text { hingga } 5 \text { tingkat } \\
\text { krak }\end{array}$ & $\begin{array}{l}\text { Tejepit, } \\
\text { Pinggang } \\
\text { terkilir }\end{array}$ & & $\begin{array}{c}5 \\
\text { Important }\end{array}$ & $\begin{array}{c}6 \\
\text { Freque } \\
n t\end{array}$ & $\begin{array}{c}3 \\
\text { Unusual }\end{array}$ & $\begin{array}{c}90 \\
\text { Substantial }\end{array}$ \\
\hline 4 & $\begin{array}{l}\text { Menaikan } 5 \\
\text { tingkat krak } \\
\text { kedalam Mobil }\end{array}$ & $\begin{array}{l}\text { Tertimpa } \\
\text { Krak }\end{array}$ & $\mathrm{D}$ & $\begin{array}{c}5 \\
\text { Important }\end{array}$ & $\begin{array}{c}1 \\
\text { Rare }\end{array}$ & $\begin{array}{c}3 \\
\text { Unusual }\end{array}$ & $\begin{array}{c}15 \\
\text { Acceptable }\end{array}$ \\
\hline
\end{tabular}

Berdasarkan skor analisi resiko tersebut kemudian dilakukan evaluasi resiko. Evaluasi resiko berdasarkan tingkat resiko yang merupakan hasil perkalian dari variabel konsekuensi, paparan, dan kemungkinan. Tingkat resiko kemudian pekerjaan di masukan dalam kategori resiko untuk analisis semi kuantitatif. Berikut merupakan hasil evalusi resiko yang di jabarkan pada tabel yang disajikan dalam Tabel 7.

Tabel 7. Hasil evaluasi risiko

\begin{tabular}{|c|c|c|c|c|c|}
\hline No & Rincian Pekerjaan & Resiko & Tingkat & $\begin{array}{l}\text { Kategori } \\
\text { Resiko }\end{array}$ & Rekomendasi \\
\hline \multirow[t]{3}{*}{1} & $\begin{array}{l}\text { Menyalakan power } \\
\text { mesin }\end{array}$ & $\begin{array}{l}\text { Tersetrum, } \\
\text { Terjatuh } \\
<1 \mathrm{~m}\end{array}$ & 15 & Acceptable & $\begin{array}{l}\text { Memasang Warning Sign agar pekerja } \\
\text { lebih hati-hati, memasang tangga atau } \\
\text { handrail untuk tempat yang mempunyai } \\
\text { resiko terjatuh, Sosialisasi penggunaan } \\
\text { PDA, memberikan reward and } \\
\text { punishment pada pekerja. }\end{array}$ \\
\hline & $\begin{array}{l}\text { Memasukkan bahan } \\
\text { pengemas sesuai } \\
\text { jenis produk }\end{array}$ & $\begin{array}{l}\text { Terjatuh } \\
<1 \mathrm{~m}\end{array}$ & 15 & Acceptable & $\begin{array}{l}\text { Memasang Warning Sign agar pekerja } \\
\text { lebih hati-hati, memasang tangga atau } \\
\text { handrail untuk tempat yang mempunyai } \\
\text { resiko terjatuh, Sosialisasi pentingnya } \\
\text { penggunaan PDA, memberikan reward } \\
\text { and punishment pada pekerja. }\end{array}$ \\
\hline & $\begin{array}{l}\text { Flusing Mesin } 1 \\
\text { sampai Mesin } 17\end{array}$ & Terpeleset & 30 & Priority 3 & $\begin{array}{l}\text { Memasang Warning Sign terkait dengan } \\
\text { resiko yang ditimbulkan, Memasang } \\
\text { penghalang dan penampung agar air } \\
\text { tidak jatuh ke lantai, Sosialisasi } \\
\text { pentingnya penggunaan PDA, } \\
\text { memberikan reward and punishment } \\
\text { pada pekerja. }\end{array}$ \\
\hline \multirow[t]{2}{*}{2} & $\begin{array}{l}\text { Menggantijalur pipa } \\
\text { air ke jalur susu }\end{array}$ & Terpeleset & 30 & Priority 3 & $\begin{array}{l}\text { Memasang Warning Sign terkait dengan } \\
\text { resiko yang ditimbulkan, Memas ang } \\
\text { penghalang dan penampung agar air } \\
\text { tidak jatuh ke lantai, Sosialisasi } \\
\text { pentingnya penggunaan PDA, } \\
\text { memberikan reward and punishment } \\
\text { pada pekerja. }\end{array}$ \\
\hline & $\begin{array}{l}\text { Mengatur volume } \\
\text { dan pemasangan } \\
\text { kemasan minipack }\end{array}$ & $\begin{array}{l}\text { Luka Bakar, } \\
\text { Terpotong }\end{array}$ & 270 & Priority 1 & $\begin{array}{l}\text { Memasang Warning Sign terkait dengan } \\
\text { resiko yang ditimbulkan, Menyediakan } \\
\text { sarung tangan untuk semua operator, } \\
\text { sosialis asi pentingnya penggunaan PDA, } \\
\text { memberikan reward and punishment } \\
\text { pada pekerja. }\end{array}$ \\
\hline No & Rincian Pekerjaan & Resiko & Tingkat & $\begin{array}{l}\text { Kategori } \\
\text { Resiko }\end{array}$ & Rekomendasi \\
\hline
\end{tabular}




\begin{tabular}{|c|c|c|c|c|c|}
\hline 3 & $\begin{array}{l}\text { Mengemas susu } \\
\text { minipack ke dalam } \\
\text { plastic }\end{array}$ & $\begin{array}{l}\text { Terpapar } \\
\text { dingin }\end{array}$ & 100 & Substansials & $\begin{array}{l}\text { Memasang Warning Sign terkait dengan } \\
\text { resiko yang ditimbulkan. Menyediakan } \\
\text { kaos tangan yang memadai untuk semua } \\
\text { operator, Sosialisasi pentingnya } \\
\text { penggunaan PDA, memberikan reward } \\
\text { and punishment pada pekerja. }\end{array}$ \\
\hline
\end{tabular}

$\begin{array}{llll}\begin{array}{l}\text { Menempatkan } \\ \text { plastik minipack ke } \\ \text { dalam krak hingga 5 }\end{array} & \begin{array}{l}\text { Terjepit, } \\ \text { Pinggang } \\ \text { tingkat krak }\end{array} & 90 \quad \text { Substansials } & \begin{array}{l}\text { Memasang Warning Sign terkait dengan } \\ \text { resiko yang ditimbulkan, memperbaiki }\end{array} \\ & & \begin{array}{l}\text { layout kerja, Sosialisasi pentingnya } \\ \text { penggunaan PDA, memberikan reward } \\ \text { and punishment pada pekerja. }\end{array}\end{array}$

\begin{tabular}{lllll}
\hline Menaikan 5 tingkat & Tertimpa & 15 & Acceptable & $\begin{array}{l}\text { Memasang Warning Sign terkait dengan } \\
\text { krak kedalam Mobil }\end{array}$ \\
& Krak & & $\begin{array}{l}\text { pentingnya penggunaan PDA, } \\
\text { memberikan reward and punishment } \\
\end{array}$ \\
& & & \begin{tabular}{l} 
pada pekerja. \\
\hline
\end{tabular}
\end{tabular}

\section{Pembahasan}

Warining sign dapat disediakan tergantung dengan jenis pekerjaannya. Warning sign ini harus mendapatkan perhatian [15]. Peringaran dapat disajikan secara visual (tanda atau label) maupun auditory (suara atau ucapan) [15]. Peringatan tersebut harus mengundang perhatian pekerja sesuai dengan jenis pekerjaannya. Apabila pekerjaan tersebut terkait dengan pekerjaan yang memerlukan detail dari langkah-langkah pekerjaan, maka dapat diberikan peringaran berupa label maupun tanda. Namun apabila pekerjaan tersebut membutuhkan fokus dan ketelitian, maka dapat menggunakan peringatan berupa suara selama periode waktu tertentu. Pekerjaan ini contohnya adalah pekerjaan bagian pengemasan. Pekerjaan ini membutuhkan fokus ketelitian dalam mengemas, sehingga diperlukan peringatan berupa suara agar fokus tidak terpecah.

CV. XYZ dapat membentuk Panitia Pembina Keselamatan dan Kesehatan Kerja (P2K3). Dasar hukum pembentukan ialah Permenaker RI Nomor PER.04/MEN/1987 tentang Panitia Pembina Keselamatan dan Kesehatan Kerja serta Tata Cara Penunjukan Ahli Keselamatan Kerja [11].

CV. XYZ memiliki 117 orang pekerja. Pada proses produksi memiliki resiko besar terjadinya kecelakaan akibat kerja terutama pada bagian minipack dibagian pemasangan volume dan kemasan. P2K3 memiliki tugas yang terdapat dalam pasal 4 ayat 2 .

Pasal 4 ayat 2 tersebut menjabarkan bahwa dengan adanya P2K3, maka CV. XYZ sebenarnya dapat ikut terbantu untuk mengatasi masalah-masalah yang ada. Sehingga menurut penjelasan tersebut perusahaan ini perlu membentuk P2K3.

Selain itu CV. XYZ perlu melakukan suatu langkah pendekatan perilaku untuk memaksimalkan penerapan K3. Salah satu langkah yang dapat dilakukan melalui pendekatan perilaku adalah Behavior Based Safety (BBS). Behavior Based Safety (BBS) adalah sebuah proses yang menciptakan kemitraan keamanan antara manajemen dan tenaga kerja dengan fokus yang berkelanjutan terhadap perhatian dan tindakan setiap orang, dan orang lain, serta perilaku selamat [2].

Berdasarkan proses BBS diatas, diketahui langkah pertama yang dilakukan adalah mengidentifikasi perilaku yang berbahaya dari para pekerja. Selanjutnya hasil identifikasi dibahas secara bersama dengan manajemen. Langkah selanjutnya adalah melakukan observasi pada pekerja yang sedang melakukan pekerjaannya. Hasil temuan observasi selanjutnya direkap pada suatu dokumen. Berikan tanggapan positif jika perilaku aman dilakukan oleh pekerja, berikan koreksi jika perilaku bahaya dilakukan. Langkah berikutnya komunikasikan hasil analisa kepada para pekerja. Jika memungkinkan berikan penghargaan kepada pekerja yang memiliki perilaku kerja yang paling baik dan aman. 


\section{Kesimpulan dan Saran}

Berdasarkan peneltian yang telah dilakukan, dapat disimpulkan bahwa identifikasi resiko menggunakan Job Safety Analysis diketahui bahwa tiap pekerjaan pada bagian pengemasan minipack telah mempunyai pengendalian resiko tetapi belum optimal.

Berdasarkan perhitungan analisis resiko semi kuantitatif menggunakan AS/NZS 4360 (1999) [1], pekerjaan yang memiliki nilai resiko kecelakaan kerja tertinggi adalah pekerjaan mengatur volume dan pemasangan kemasan minipack dengan skornilai 270.

Pengendalian resiko yang dapat dilakukan oleh CV XYZ untuk mengurangi kecelakaan kerja adalah memberikan warning sign, membentuk tim P2K3 dan menerapkan Behavior Based Safety (BBS) bagi keseluruhan pekerja.

\section{Ucapan Terima Kasih}

Peneliti mengucapkan terimakasih kepada Prodi Teknik Industri, Fakultas Teknologi Industri, Universitas Islam Indonesia atas dukungan yang diberikan.

\section{Daftar Pustaka}

[1] Committee OB/7, Retrieved from Risk Management AS/NZS 4360:1999, 2016. (online): http://thirdeyeriskinsight.com/articles (12 Maret 2017).

[2] Cooper, D., Behavioral Safety a Framework for Success, Indiana: BSMS Inc. (2009).

[3] Cross, J. Study Notes SESC9211 Risk Management. Sidney: Department of Safety Science University of New South Wales. (1998).

[4] Danjuma, A., Babatunde, A.A.-L., Taiwo, O.A., Micheal, S.N., Rates and patterns of operating room hazards among Nigerian perioperative nurses, J. Perioper. Crit. Intens. Care Nurs. (2016).

[5] Geigle, Steven, OSHAcademy Course 706 Study Guide Conducting a Job Hazard Analysis. Oregon : Geigle Communications. (2002).

[6] Gopang, M.A., Nebhwani, M., Khatri, A., Marri, H.B., An assessment of occupational health and safety measures and performance of SMEs: An empirical investigation, Safety science. 93 (2017) 127-133.

[7] Gopinath, Varun, and Kerstin Johansen, Risk Assessment Process for Collaborative Assemb ly-A Job Safety Analys is Approach, Procedia CIRP44 (2016): 199-203.

[8] Jaiswal, Vinit.; Banodha, Vineet dan Patel, Praveen. 2014. Risk Assessment in Maintenance Work at Diesel Locomotive Workshop. International Journal on Emerging Technologies. 5(1): 59-63(2014) ISSN No. (Online) : 2249-3255

[9] Morrish, C., Incident prevention tools-incident investigations and pre-job safety analyses, International Journal of Mining Science and Technology. 4.27 (2017): 635-640.

[10] Novianto, Farid., Analisis Kecelakaan dan Kesehatan Kerja dan Upaya Pencegahannya di Bagian Flooring dengan Pendekatan Risk Assesment PT. Dharma Satya Nusantara Surabaya. Skripsi. Fakultas Teknologi Industri. Universitas Pembangunan Nasional "Veteran”: Jawa Timur. (2010).

[11] Peraturan Menteri Tenaga Kerja, Panitia Pembina Keselamatan Dan Kesehatan Kerja Serta Tata Cara Penunjukan Ahli Keselamatan Kerja Nomor : PER.04/MEN/1987, Menteri Tenaga Kerja Republik Indonesia. (1987).

[12] Ramli, S., Sistem Manajemen Keselamatan dan Kesehatan Kerja OHSAS 1800,. Jakarta: Dian Rakyat. (2010).

[13] Sucipto, CD., Keselamatan dan Kesehatan Kerja, Yogyakarta: Gosyen Publishing. (2014).

[14] Suma'mur, Keselamatan Kerja dan pencegahan Kecelakaan, Jakarta: CV. Haji Masagung.(1996).

[15] Wolgater, M.S., and Laughery, K.R., Warning! Sign and label Effectiveness. Current Directions in Pshycological Science. (1996). 